\title{
Leveraging High Resolution Signalized Intersection Data to Characterize Discharge Headway Distributions and Saturation Flow Rate Reliability
}

by

Stephen M. Remias

Purdue University

Alexander M. Hainen

Purdue University

Gannon M. Grimmer

Purdue University

Alexander D. Davis

Purdue University

Christopher M. Day

Purdue University

Thomas M. Brennan

Purdue University

James R. Sturdevant

Indiana Department of Transportation

Corresponding Author:

Darcy Bullock, P.E.

Purdue University

May 8, 2014

TRB Paper No. 12-2122

Word Count: 1852 words $+11 * 250$ words/table $=\mathbf{4 , 4 6 9}$ words 


\section{ABSTRACT}

As highway systems become more congested, it becomes increasingly important to understand the reliability with which we can estimate important performance measures such as volume to capacity ratios, particularly as we move toward leveraging field infrastructure to obtain real-time performance measures. In 1947, Greenshields wrote a paper that characterized "green time consumed" by "car-in-line-number" that ultimately was called headway. Average headway is one of principles used by the highway capacity manual to estimate saturation flow rate at signalized intersections. However, the current analytical techniques calculate a deterministic value for saturation flow rate that does not consider the stochastic variation of saturation flow rate. This paper reviews techniques used to estimate saturation flow rate, and proposes enhanced calculation methods to group saturation flow rate estimates by queue length. Grouping saturation flow rate estimates by queue length provides a convenient framework to evaluate saturation flow rate reliability.

The inter-quartile range (25\% - 75\%) of saturation flow rates was calculated to be $1000 \mathrm{vph}$ based on Greenshields' calculation techniques. Using the proposed enhanced calculation characterizing saturation flow rate, the inter-quartile range of saturation flow rate was shown to decrease from approximately 400 vph with 5 cars in a queue to 300 vph with 10 cars in queue. Because saturation flow rate is a fundamental input to volume-to-capacity performance measures, characterizing the stochastic variation of saturation flow rates provides a basic input for assessing how reliably one can estimate important performance measures such as volumeto-capacity ratios, as well as other performance measures that build upon volume-to-capacity ratios. 


\section{INTRODUCTION}

In 1947, Greenshields conducted an extensive study of the behavior of vehicles at signalized intersections [1]. In this work film footage of traffic was combined with a transparency grid to analyze vehicle headways at intersections in Connecticut. Among many other observations this work characterized "green time consumed" by "car-in-line-number" (see Figure 1). He also noted that for the sixth vehicle and beyond, the mean green time consumed was approximately 2.1 seconds. This "green time consumed" is analogous to what we now call "headway," which relates to the saturation flow rate by the following relationship:

$$
s=\frac{3600}{\bar{h}}
$$

where $s$ is the saturation flow rate in vehicles per hour (vph) and $\bar{h}$ represents the average headway in seconds. Saturation flow rate is a crucial input to the $\operatorname{HCM}[2,3,1]$ equations for a variety of capacity calculations.

In the area of signalized intersections, Eq. 2 is the basic equation for calculating the capacity of a single lane:

$$
c=\left(\frac{g}{C}\right) s
$$

Here, $c$ is the saturated capacity in vph, $g$ is the effective green time in seconds, and $C$ is the signal cycle length in seconds.

The ratio of the demand volume to the capacity calculated in Eq. 2 is used to calculate the degree of saturation $X_{i}$ for a movement using Eq. 3:

$$
X_{i}=\frac{v}{s} \frac{C}{g_{i}},
$$

where $v$ is the demand flow rate in vph.

As $X_{i}$ increases, the probability that a split failure occurs also increases [6, 7]. A split failure can be defined as an instance where not all of the demand for a movement is served by the green time given to a phase. All of the quantities in Eq. 3 can be measured with automatic data collection $[6,7,8]$, with the exception of saturation flow rate, $s$. 
From Eq. 3, it is clear that the selected value of $s$ has a profound impact on the reported degree of saturation. The factor scales the metric, and relative differences in $s$ among phases at an intersection will strongly affect the relative reported performance of those phases. The Highway Capacity Manual has detailed procedures for estimating saturation flow rate that have matured over the years $[3,4,1]$ Several methods for directly measuring saturation flow rates in the field have also been developed. These include use of observed headways [9, 10, 11, 12, 13], regression analysis based on other observable quantities [15, 16], analysis of vehicle counts during saturated green [17], and models of driver behavior [18]. As a result of continued research and observations, saturation flows have gradually increased over the years. Saturation flows have additionally been shown to vary considerably by location and other factors $[19,20$, 21, 22].

In practice, however, field measurement of saturation flow rates is not typically done because of the considerable amount of equipment and labor required. The HCM [1] provides a methodology for determining $s$ incorporating lane width, heavy vehicle proportion, grade, area, turning movement proportions, and other factors to estimate saturation flow rate for lanes. However, it is silent on the stochastic variation of this quantity over time. As a result of this uncertainty in saturation flow, as intersections movements approach saturation it is unclear how effectively Eq. 3 predicts when oversaturation and split failure will occur. Impacts of uncertainty in parameters such as saturation flow rate have been shown to substantially impact the ability of the analyst to accurately describe system performance [23].

As real time intersection performance measures mature, it is critical to develop scalable procedures to directly estimate saturation flow rate from field equipment instead of relying on $\mathrm{HCM}$ estimation techniques or field procedures. With high-resolution data collection, it now becomes possible to begin developing automated procedures for measuring saturation flow rates to validate assumptions used in performance measurement $[6,7]$.

\section{PROBLEM STATEMENT}

This paper seeks to use modern high-resolution intersection data collection techniques and technology to collect headway statistics similar to Greenshields' procedure, as well as a variation on those data collection techniques that may provide a more robust indicator of true saturation flow rates and their stochastic variation.

\section{METHODOLOGY}

Greenshields' approach to measure headways employed substantial field photography. Recently, traffic technologies have evolved to the point where a semi-automated process has been established to gather and interpret large quantities of data at an intersection $[6,7,8]$. Using three intersections in an Indianapolis study corridor (Figure 2) vehicle departure times were measured to capture data necessary to characterize the statistical distribution of departure headways under saturated conditions [11]. 
Wireless magnetometers were installed at the exiting approach of each of the three intersections. Figure $2 \mathrm{a}, \mathrm{b}$, and $\mathrm{c}$ show that there are magnetometers placed in two lanes in the eastbound direction (01-EA, 01-1b, 02-EA, 02-EB, 03-EA, and 03-EB) and in a single lane in the westbound direction (01-WA, 02-WA, and 03-WA). The wireless magnetometers were placed approximately 200 feet from the corresponding stop bar, the exact distances and intersection IDs are listed in Table 1.Pan-Tilt-Zoom (PTZ) cameras were also installed at each of the intersections along the corridor and used to count the number of cars in queue at the start of green. Figure $3 a$ and $b$ show an example of the camera at the Post Road intersection facing the eastbound stopbar.

The data were recorded over a two-day period on July $7^{\text {th }}$ and $8^{\text {th }}$ of 2011 . Since the goal of the study was to capture saturated conditions at the intersections, the cameras monitored the westbound approaches during the AM period and the eastbound approaches for the PM periods. The location of the corridor is just on the east side of Indianapolis, so this corresponds with vehicles travelling to and from the downtown area. Using the wireless magnetometer data, the peak three hour periods (AM Peak 0700 - 1000, PM Peak 1600 - 1900) were determined and used to evaluate the saturation conditions. The videos were then manually processed over these periods and used to determine the beginning of green time and the number of vehicles in the queue that came to a complete stop. Once the beginning of green times and number of vehicles were determined, the wireless magnetometer data was queried to find the headway between the vehicles that had been counted. Vehicles were only included if they had come to a complete stop at the intersection.

An example of the process is shown in Figure $3 a$ where 9 cars can be seen queued at the eastbound stopbar of Pendleton Pike at Post Road. The start of green time was manually recorded when the first vehicle began to move through the intersection. The wireless magnetometers, placed at the other side of the intersection recorded the exiting times, which were used to determine headway. Figure $3 b$ shows the headway between vehicle numbers 3 and 4 , where the beginning of the platoon dispersion can be observed.

\section{ESTIMATION OF SATURATION FLOW RATE}

Figure 4 shows the headway distributions of consecutive cars during saturated conditions at the study corridor. Due to a technical problem, the electronic log of the start of green time to the nearest 0.1 second was not recorded (this issue has since been resolved and can be included in revised manuscript if requested). The sample sizes are shown for each of the headway bins. As one would expect, the sample size for headways between veh 1 and veh 2 in the queue (Figure 4a: $n=690$ ) is larger than the sample size for the headways between veh 8 and 9 in the queue (Figure $4 \mathrm{~h}: \mathrm{n}=223$ ). These distributions were then used to construct Figure $5 \mathrm{a}$, which is similar plot to Greenshields' study seen in Figure 1a. Instead of using the standard deviation for the range bars as Greenshields used, the $25^{\text {th }}$ and $75^{\text {th }}$ percentile headways were plotted to accompany the median. The numerical representations of these figures, along with the sample sizes, means, and standard deviations can be seen in Table 2. Not surprisingly, comparing 
Figure $5 a$ and Figure 1a, the headways are significantly lower in this study than in Greenshields' 1947 study. This is consistent with observations by the highway capacity community [3, 4, 1].

To the impact how the stochastic headway impacts estimates of saturation flow rate, Figure $5 b$ illustrates the $25^{\text {th }}$, median, and $75^{\text {th }}$ percentile saturated flow rates in vehicles per hour calculated from the data set shown in Figure 4. The median saturated flow rates remained relatively consistent across all of the vehicles in the queue, approaching 2000 vehicles per hour.

\section{NEW PERSPECTIVE ON ESTIMATING SATURATION FLOW RATE AND RELIABITY}

Instead of viewing the headways from consecutive vehicles (1-2, 2-3, 3-4, etc.), a better approximation of how vehicles are reacting as a whole can be characterized by looking at the headways with vehicle 1 as the baseline (1-2, 1-3, 1-4, etc.). Figure 6 plots the histogram of headways between the first vehicle and the $\mathrm{n}^{\text {th }}$ vehicle. The Figure $6 \mathrm{a}$ histogram is clustered around 2 seconds, because it corresponds to the headway between two successive vehicles. The Figure 6h histogram is clustered around 16s, because it corresponds to the headway between the $1^{\text {st }}$ and $9^{\text {th }}$ vehicle.

Using the distributions from Figure 6 , the $25^{\text {th }}$, median, and $75^{\text {th }}$ percentile headway times were used to construct Figure 7 to assess reliability changes as the length of the starting queue increased. Figure 7 presents this headway distribution with vehicle 1 as the baseline. The numerical data along with the statistical summary of Figure 7 can be seen in Table 3.

Using the non-consecutive vehicle headways shown in Table 3, an average headway can be determined for each vehicle in queue. This means that if there are a specific number of cars in a queue, the average headway between those cars can be determined. Figure 8ashows the data from Figure 7 normalized by the number of headways and Figure $8 b$ show the data from Figure $8 \mathrm{a}$, converted to saturation flow rate using Eq 1. 


\section{CONCLUSIONS}

As highway systems become more congested, it becomes increasingly important to understand the reliability with which we can estimate capacity and hence predict when congestion will occur. This requires us to understand the stochastic variation of parameters and variables in Eq. 3. This paper has reviewed techniques used to estimate saturation flow rate, and proposed slightly enhanced methods to calculate saturation flow rate and saturation flow rate reliability that can be performed using modern traffic signal control equipment and instrumentation [8, 24]. When one compares saturation flow rate estimates using legacy techniques (Figure 4), interquartile range shows little change as the number of cars in queue changes (Figure $5 b$ ). However, when one estimates saturation flow rate as a function of the number of vehicle in queue (Figure 6) the inter-quartile range of saturation flow rate appears to monotonically decrease for queue lengths up to 10 cars (Figure 8b).

We believe documenting this stochastic variation in saturation flow rate will be important to practitioners and agencies for assessing the reliability of their capacity analysis calculations.

\section{FUTURE RESEARCH}

Work is underway assemble a larger data set with queues that extend up to 20 vehicles to extend the curves shown in Figure 8 and statistically quantify the impact that weather and lighting conditions have on saturation flow rate.

\section{ACKNOWLEDGMENTS}

This work was supported in part by Sensys Networks and by the Joint Transportation Research Program administered by the Indiana Department of Transportation and Purdue University. The contents of this paper reflect the views of the authors, who are responsible for the facts and the accuracy of the data presented herein, and do not necessarily reflect the official views or policies of the sponsoring organizations. These contents do not constitute a standard, specification, or regulation. 


\section{REFERENCES}

1. Greenshields, B.D., D. Schapiro, and E.L. Erickson, "Traffic Performance at Urban Street Intersection," Technical Report No. 1, Yale Bureau of Highway Traffic, New Haven, Conn., 1947.

2. May, Adolf D., "Traffic Flow Fundamentals," Prentice-Hall, Inc. 1990.

3. "Highway Capacity Manual 1983," Transportation Research Board, National Research Council Washington, D.C., 1983.

4. "Highway Capacity Manual 2000," Transportation Research Board, National Research Council Washington, D.C., 2000.

5. "Highway Capacity Manual 2010," Transportation Research Board, National Research Council Washington, D.C., 2010.Day, C.M., D.M. Bullock, and J. R. Sturdevant, " Cycle Length Performance Measures: Revisiting and Extending Fundamentals," Transportation Research Record, \#2128, TRB, National Research Council, Washington, DC, pp.48-57, 2009.

6. Day, C.M., J.R. Sturdevant, and D.M. Bullock, "Outcome Oriented Performance Measures for Signalized Arterial Capacity Management," Transportation Research Record No. 2192, Transportation Research Board of the National Academies, Washington, DC, pp. 24-36, 2010.

7. Smaglik E.J., A. Sharma, D.M. Bullock, J.R. Sturdevant, and G. Duncan, "Event-Based Data Collection for Generating Actuated Controller Performance Measures," Transportation Research Record, \#2035, TRB, National Research Council, Washington, DC, pp.97-106, 2007.

8. Berry, D.S. and P.K. Gandhi. "Headway Approach to Intersection Capacity." Transportation Research Record No. 453, pp. 56-60, 1973.

9. Li, H. and P.D. Prevedouros. "Detailed Observations of Saturation Headways and Start-Up Lost Times." Transportation Research Record No. 1802, pp. 44-53, 2002.

10. Tong, H.Y and W.T. Hung, "Neural Network Modeling of Vehicle Discharge Headway at Signalized Intersection: Model Descriptions and Results," Transportation Research Part A, Vol. 36, pp $17-40,2002$.

11. Lin, F.-B. and D.R. Thomas. "Headway Compression During Queue Discharge at Signalized Intersections." Transportation Research Record No. 1920, pp. 81-85, 2005.

12. Xeuxiang, J. Y. Zhang, F. Wang, L. Li, D. Yao, Y. Su, and Z. Wei, "Departure Headways at Signalized Intersections: A Log-Normal Distribution Model Approach," Transportation Research Part C, Vol. 17, pp. $318-327,2009$.

13. Jang, J., C. Park, B. Kim, and N. Choi, "Modeling of Time Headway Distribution of Suburban Arterial : Case Study from South Korea," 6th International Symposium on Highway Capacity and Quality of Service, Vol. 16, pp. 240-247, 2011.

14. Branston, D. and H. van Zuylen. "The Estimation of Saturation Flow, Effective Green Time, and Passenger Car Equivalents at Traffic Signals by Multiple Linear Regression." Transportation Research, Vol. 12, pp. 47-53, 1978.

15. Kimber, R.M. and M.C. Semmens. "An Experiment to Investigate Saturation Flows at Traffic Signal Junctions." Traffic Engineering and Control, Vol. 23, pp. 110-116, 1982.

16. Transportation and Road Research Laboratory. A Method of Measuring Saturation Flow at Traffic Signals. Research Note No. 34, HMSO, London, 1963. 
17. Long, G. "Driver Behavior Model of Saturation Flow." Transportation Research Record no. 2027, pp. 65-72, 2007.

18. Teply, S. "Saturation Flow at Signalized Intersections Through a Magnifying Glass." Proc., Eighth International Symposium on Transportation and Traffic Theory, 1983.

19. Perez-Cartagena, R.I. and Tarko, A. "Predicting Traffic Conditions at Indiana Signalized Intersections." Report No. FHWA/IN/JTRP-2004/29, Joint Transportation Research Program, Purdue University, West Lafayette, IN, December 2004.

20. Perez-Cartagena, R.I. and Tarko, A. "Calibration of Capacity Parameters for Signalized Intersections in Indiana." Journal of Transportation Engineering, Vol. 131, pp. 904-911, 2005.

21. Khosla, K. and J.C. Williams. "Saturation Flow at Signalized Intersections During Longer Green Time." Transportation Research Record No. 1978, pp. 61-67, 2006.

22. Tarko, A.P. and M. Tracz. "Uncertainty in Saturation Flow Predictions." Transportation Research Circular E-C018, pp. 310-321, 2000.

23. Remias, S.M, A.M. Hainen, S.R. Mitkey, and D.M. Bullock, "Probe Vehicle Re-Identification Data Accuracy Evaluation," ITS World Congress 2011, Orlando, FL, October 2011. 


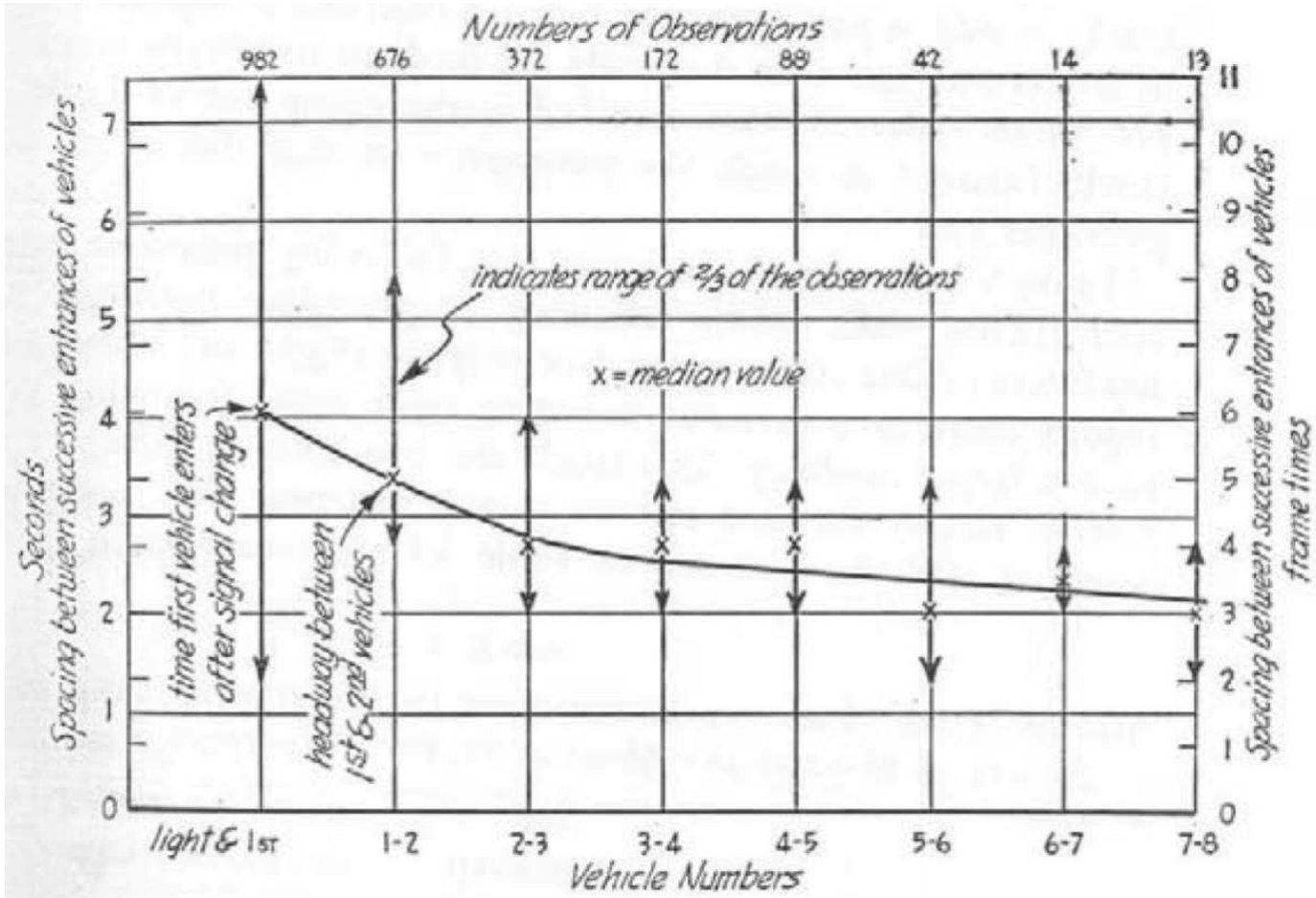

a) Time Headways between all vehicle types

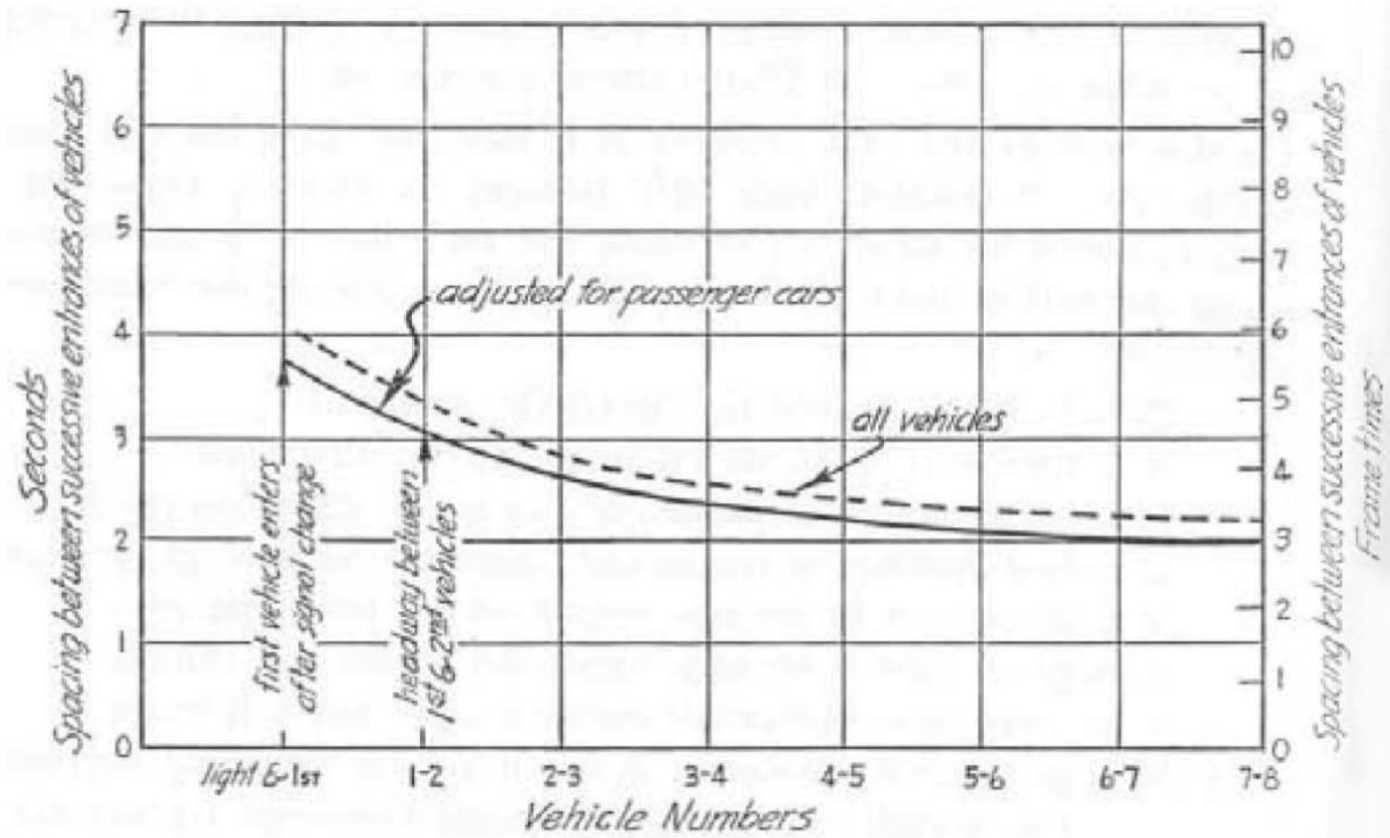

b) Time headways adjusted for passenger cars

Figure 1. Greenshields' 1947 Analysis of Headway Distributions[1] 


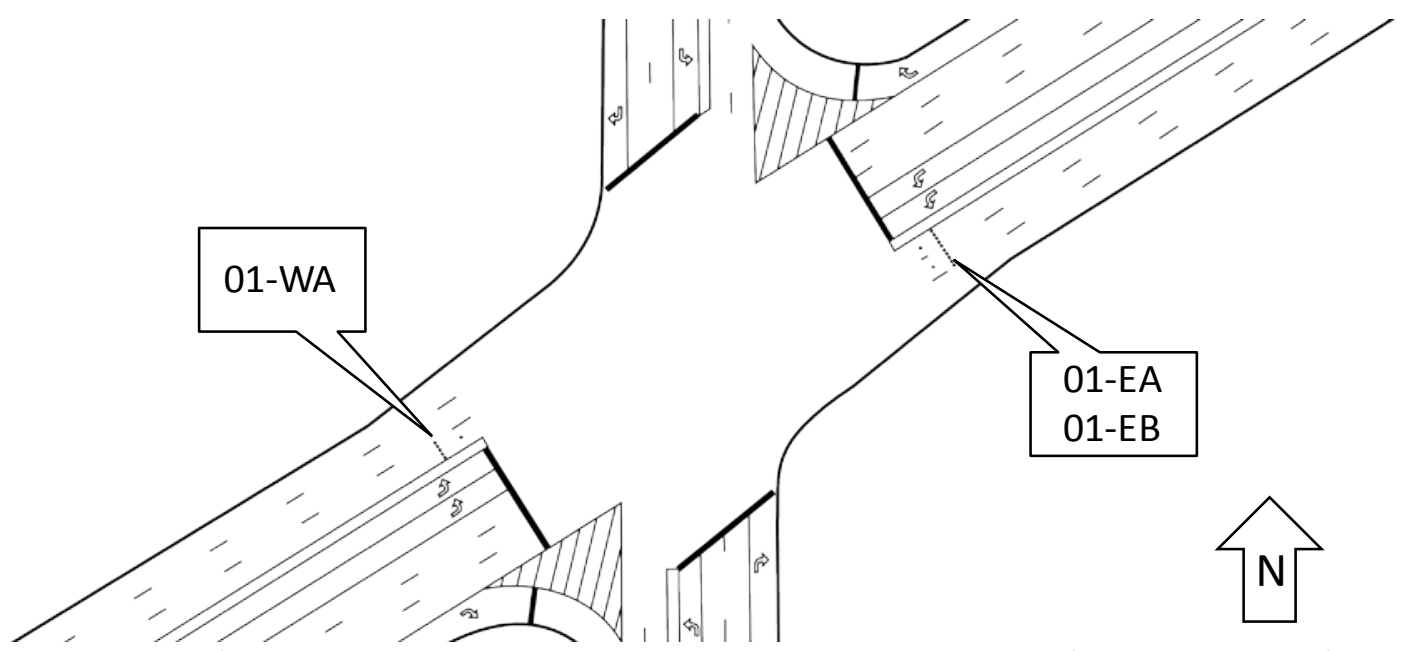

a) Intersection of Franklin Road \& Pendleton Pike (Intersection 01)

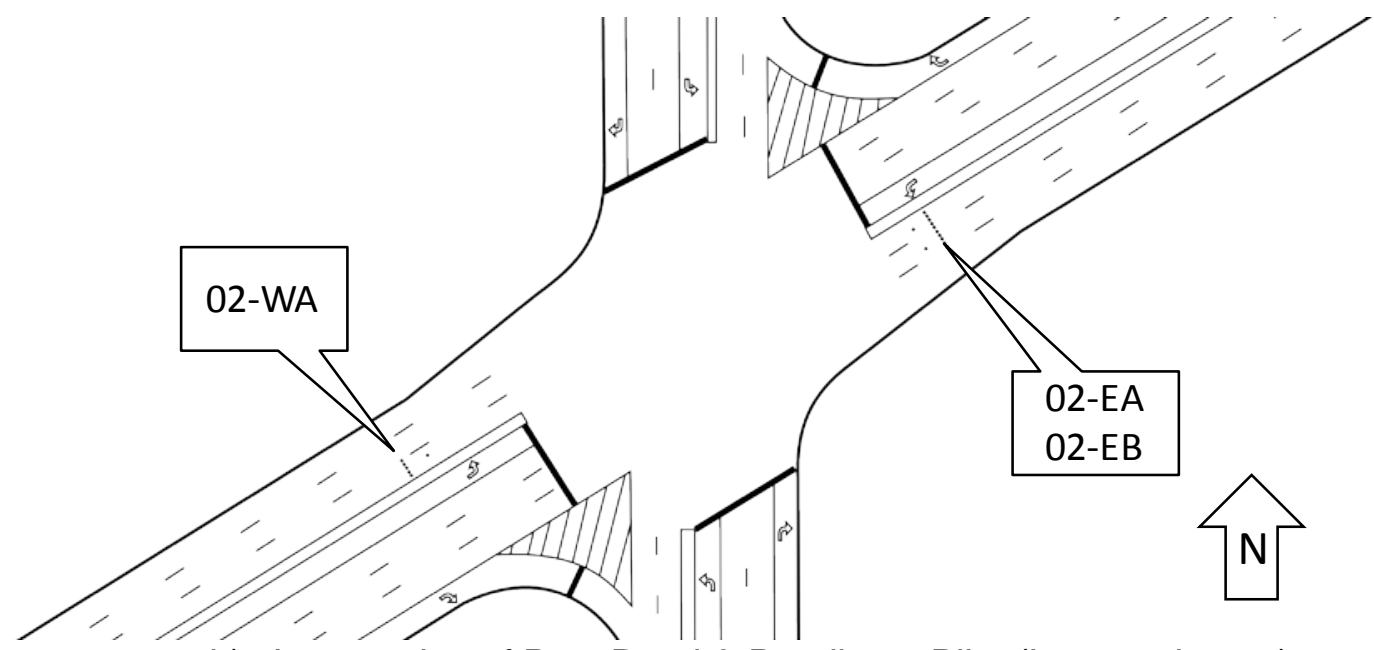

b) Intersection of Post Road \& Pendleton Pike (Intersection 02)

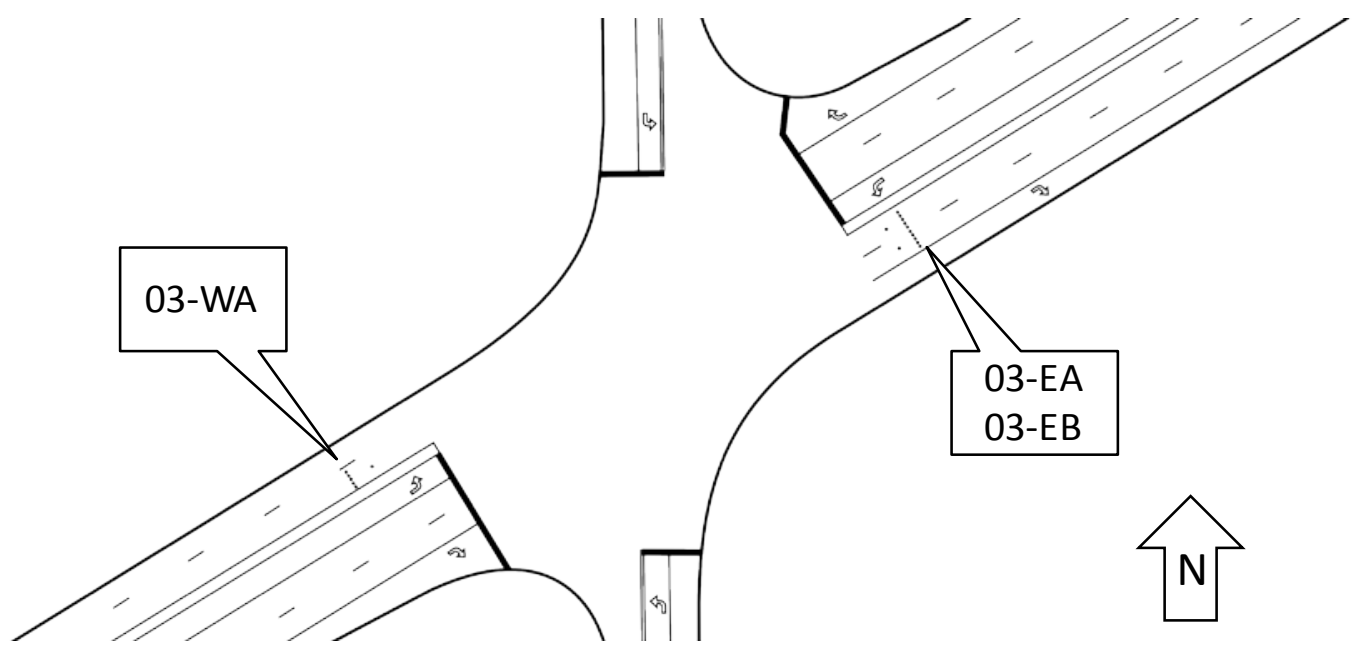

c) Intersection of Mitthoeffer Road \& Pendleton Pike (Intersection 03)

Figure 2.Installation Details for Instrumented Intersections. 


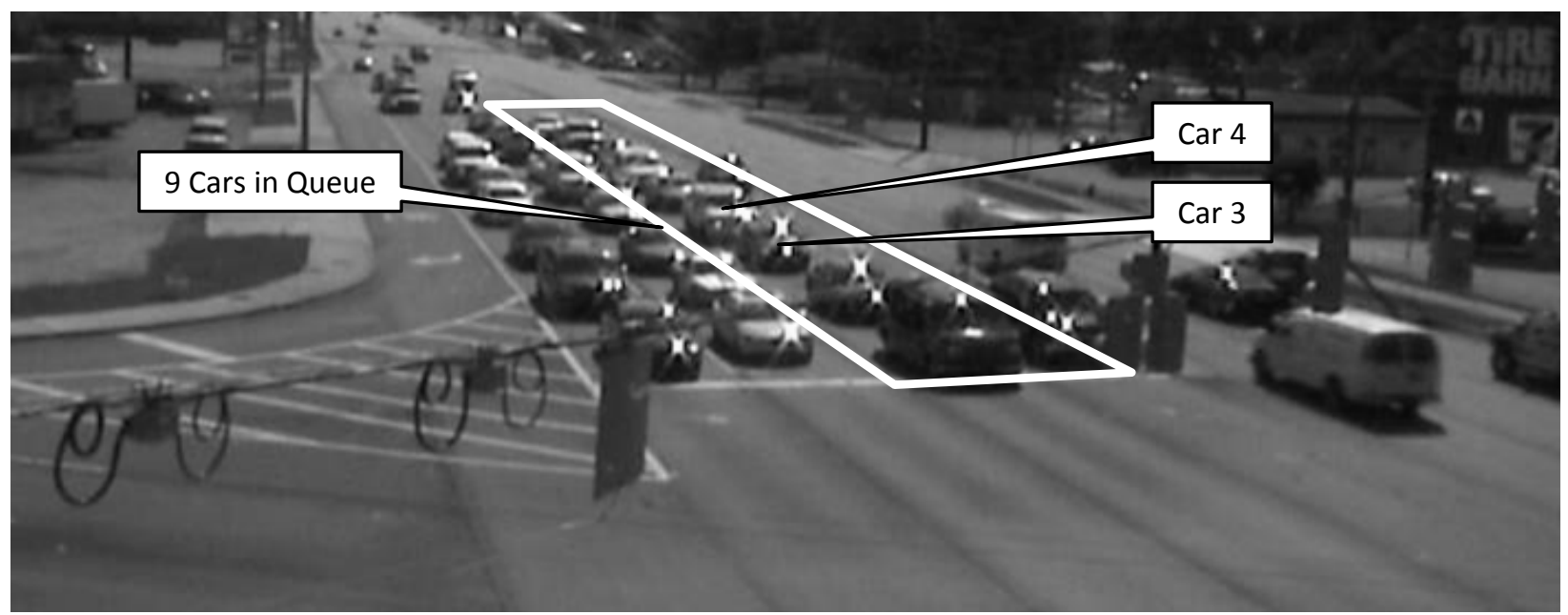

a) Queue at Red Light

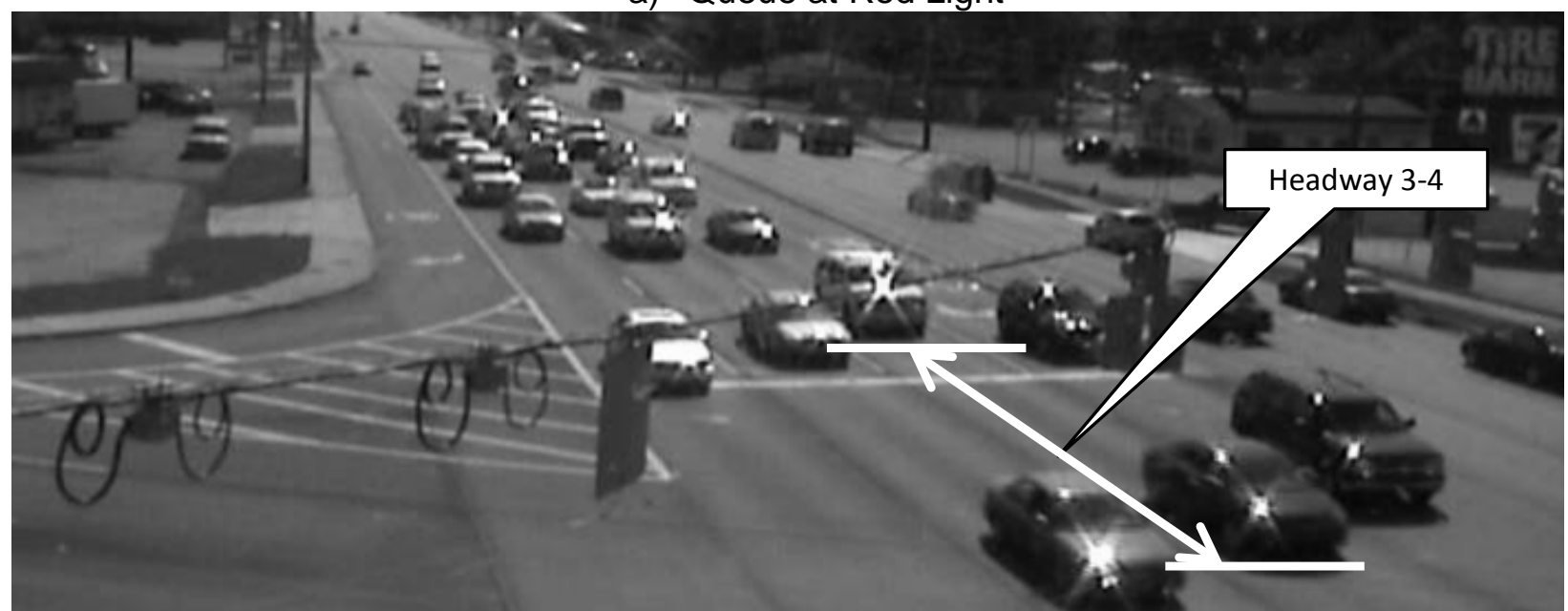

b) Time Headway between cars 3 and 4

Figure 3. EB Lane A Post Road Example of Time Headways

Table 1. Sensor Distance from Stop-Bar

\begin{tabular}{|c|c|c|}
\hline Intersection ID & Intersection & Stop Bar Offset \\
\hline 01-EA & Franklin Rd. & $218 \mathrm{ft}$ \\
\hline 01-EB & Franklin Rd. & $218 \mathrm{ft}$ \\
\hline 01-WA & Franklin Rd. & $215 \mathrm{ft}$ \\
\hline 02-EA & Post Rd. & $191 \mathrm{ft}$ \\
\hline 02-EB & Post Rd. & $191 \mathrm{ft}$ \\
\hline 02-WA & Post Rd. & $190 \mathrm{ft}$ \\
\hline 03-EA & Mitthoeffer Rd. & $223 \mathrm{ft}$ \\
\hline 03-EB & Mitthoeffer Rd. & $223 \mathrm{ft}$ \\
\hline 03-WA & Mitthoeffer Rd. & $220 \mathrm{ft}$ \\
\hline
\end{tabular}




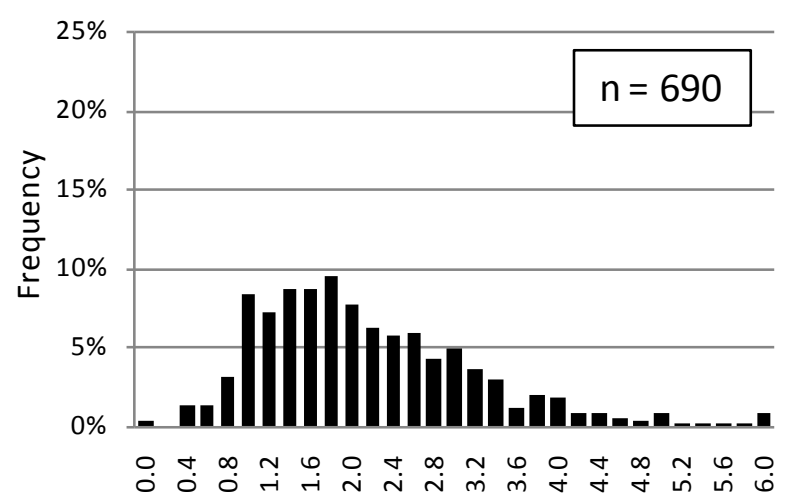

a) Headway between veh. 1 - 2

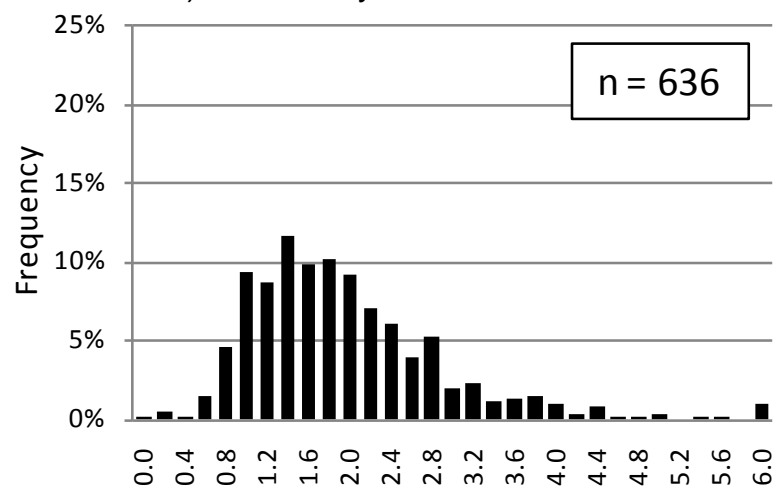

b) Headway between veh. 2 - 3

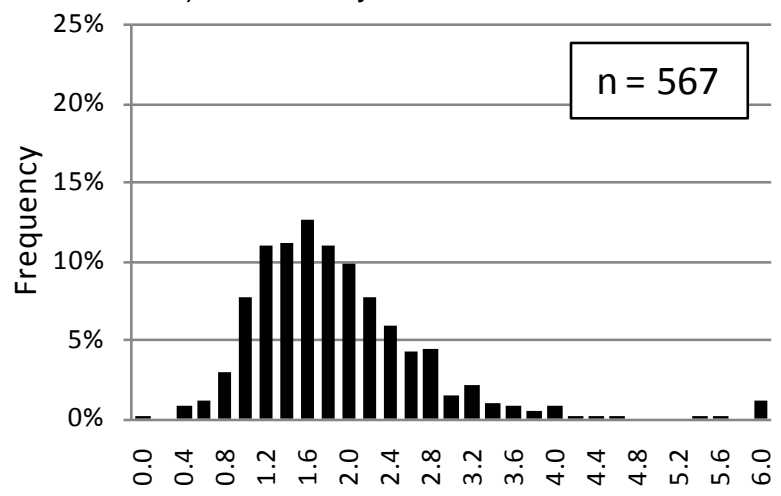

c) Headway between veh. 3 - 4

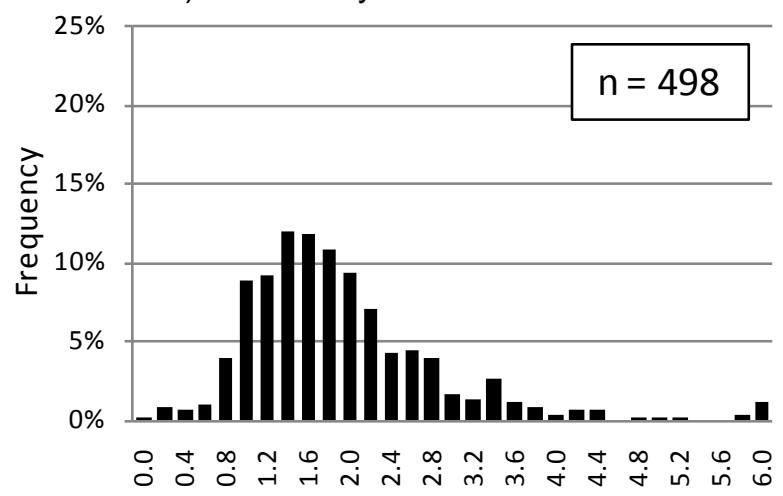

d) Headway between veh. 4 - 5

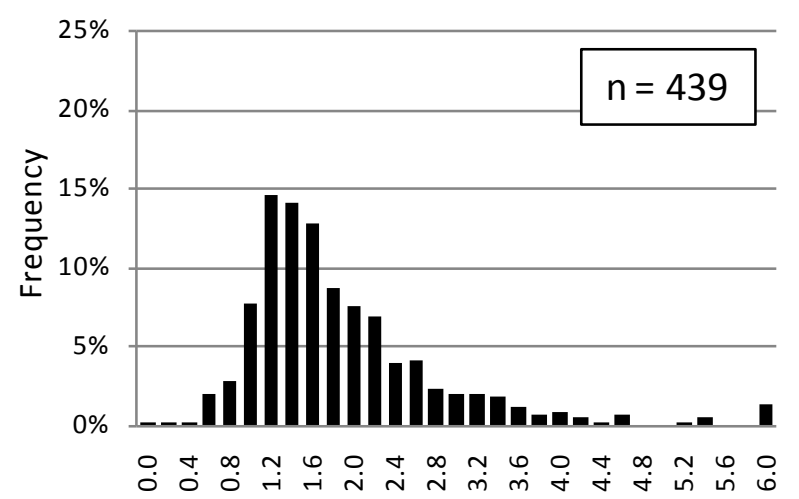

e) Headway between veh. 5 - 6

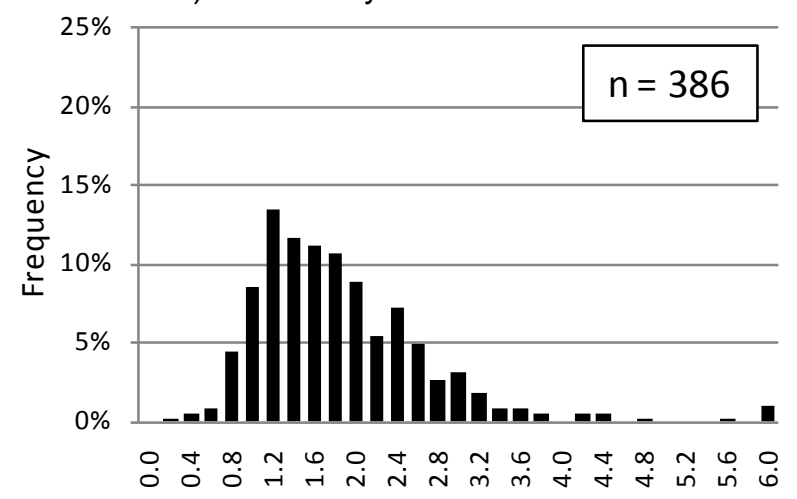

f) Headway between veh. 6 - 7

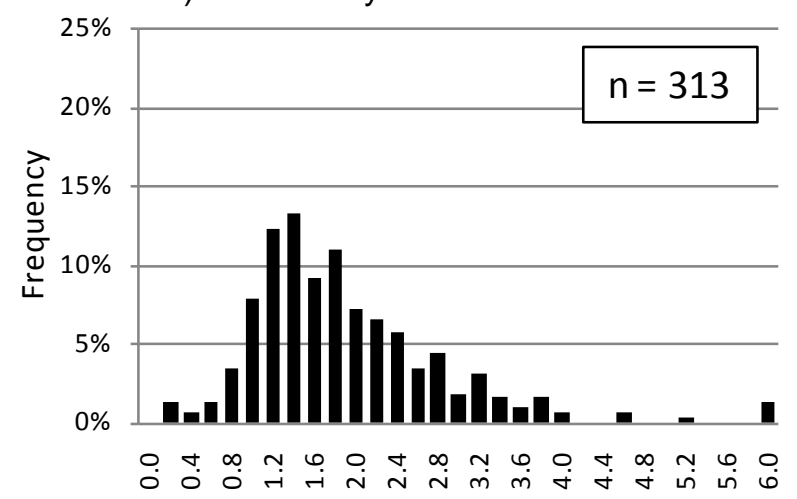

g) Headway between veh. 7 - 8

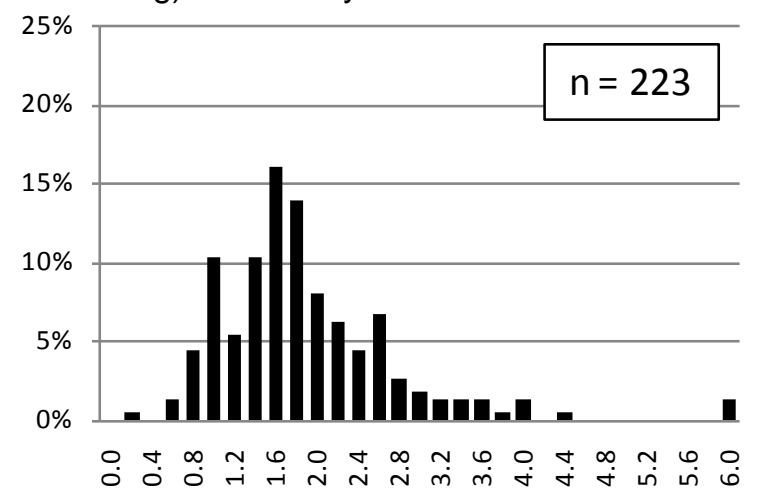

h) Headway between veh. 8 - 9

Figure 4. Headway distribution Histograms 


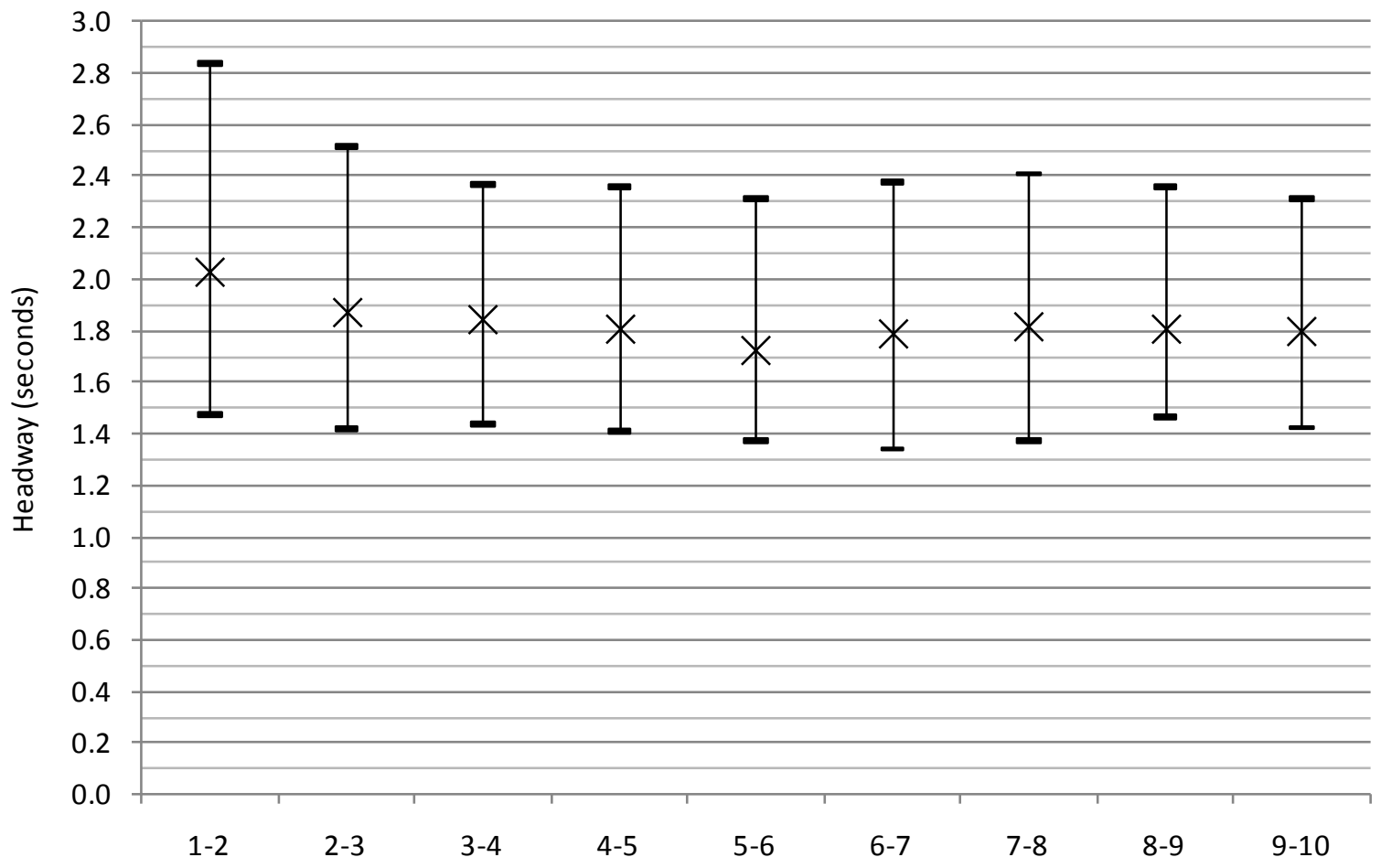

a) Headway distributions with $25^{\text {th }}$, median, and $75^{\text {th }}$ percentiles

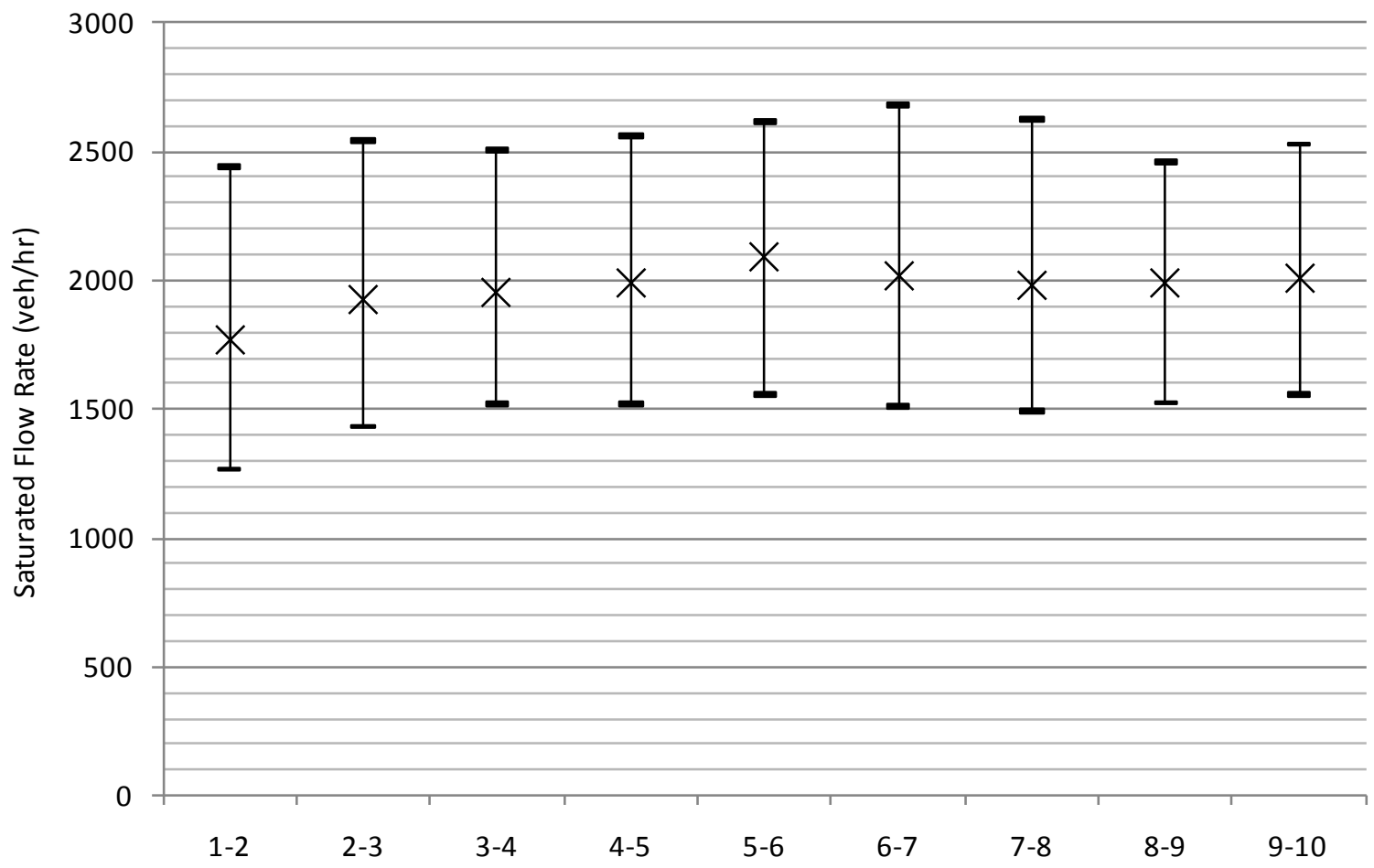

b) Saturated Flow Rates with $25^{\text {th }}$, median, and $75^{\text {th }}$ percentiles Figure 5. Characterization of Study Corridor Headways 
Table 2. Headway values between consecutive vehicles at saturated intersections

\begin{tabular}{|l|l|l|l|l|l|l|l|l|l|}
\hline Headway (seconds) & 1 to 2 & 2 to 3 & 3 to 4 & 4 to 5 & 5 to 6 & 6 to 7 & 7 to 8 & 8 to 9 & 9 to 10 \\
\hline $25^{\text {th }}$ Percentile & 1.47 & 1.42 & 1.44 & 1.41 & 1.37 & 1.34 & 1.37 & 1.46 & 1.42 \\
\hline $50^{\text {th }}$ Percentile & 2.03 & 1.87 & 1.84 & 1.81 & 1.72 & 1.78 & 1.82 & 1.81 & 1.79 \\
\hline $75^{\text {th }}$ Percentile & 2.84 & 2.51 & 2.37 & 2.36 & 2.31 & 2.38 & 2.41 & 2.36 & 2.31 \\
\hline Interquartile Range & 1.37 & 1.10 & 0.93 & 0.95 & 0.93 & 1.04 & 1.04 & 0.90 & 0.89 \\
\hline Count (n) & 690 & 636 & 567 & 498 & 439 & 386 & 316 & 223 & 172 \\
\hline Mean & 2.32 & 2.11 & 2.07 & 2.06 & 1.99 & 2.04 & 2.02 & 2.31 & 2.13 \\
\hline Standard Deviation & 1.97 & 1.49 & 1.47 & 1.38 & 1.02 & 1.70 & 1.05 & 3.95 & 1.98 \\
\hline
\end{tabular}




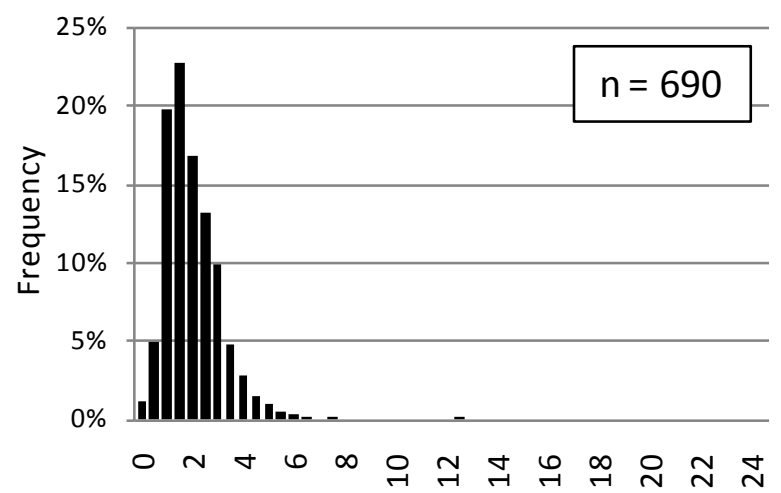

a) Headway between veh. 1 - 2

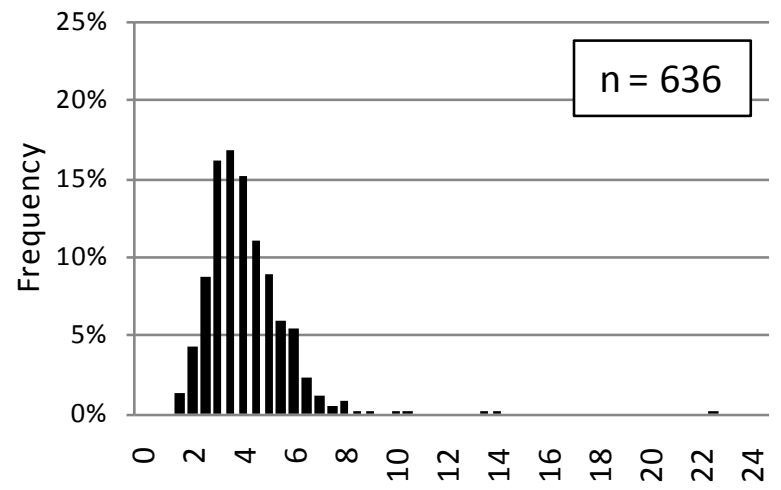

b) Headway between veh. 1 - 3

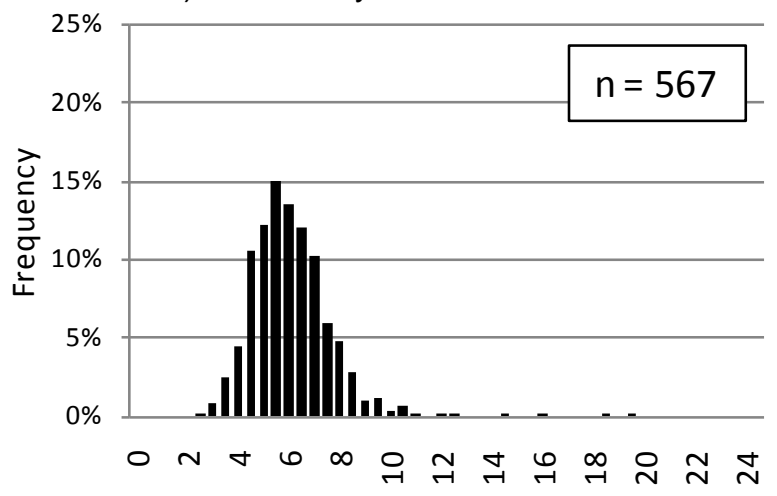

c) Headway between veh. 1 - 4

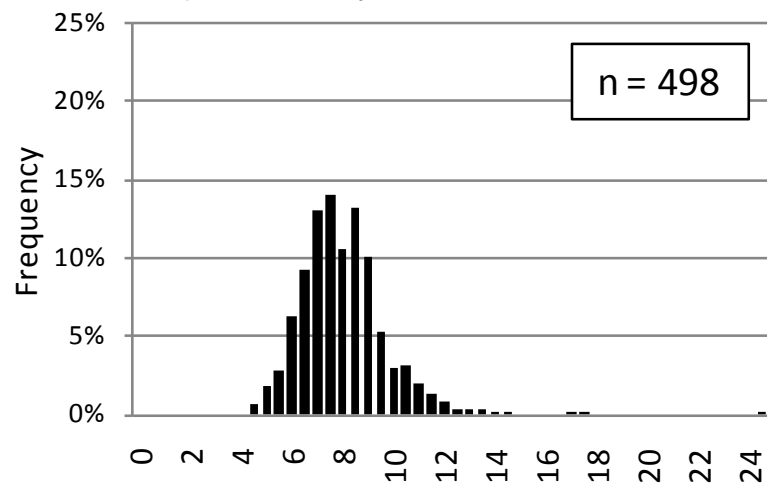

d) Headway between veh. 1 - 5

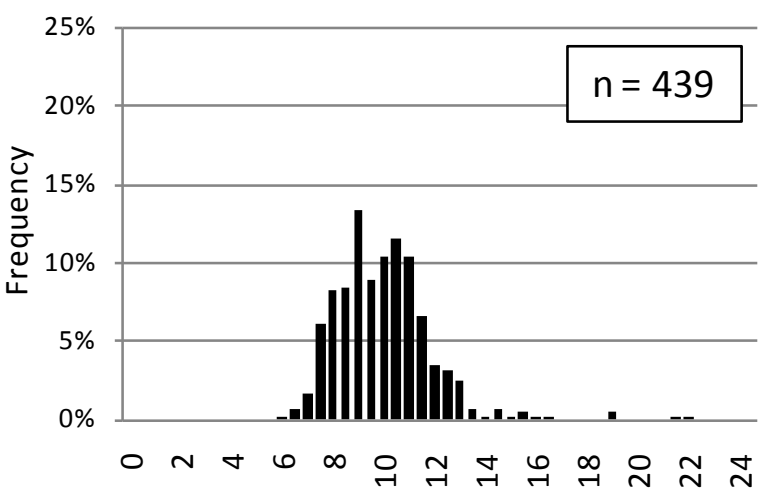

e) Headway between veh. 1 - 6

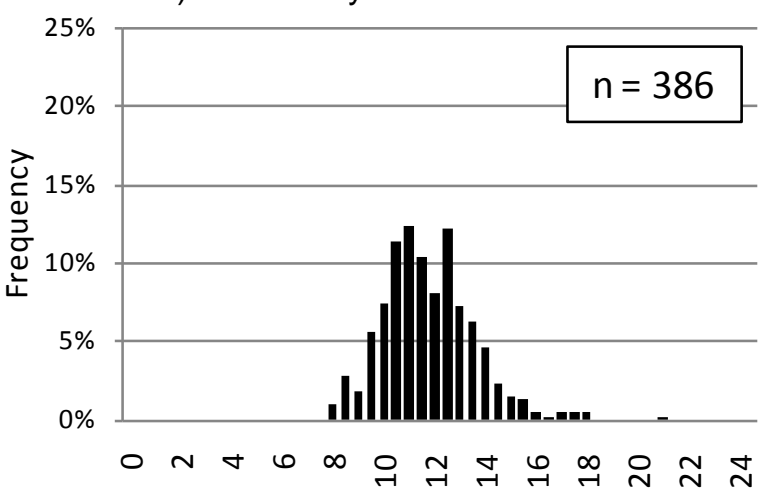

f) Headway between veh. 1 - 7

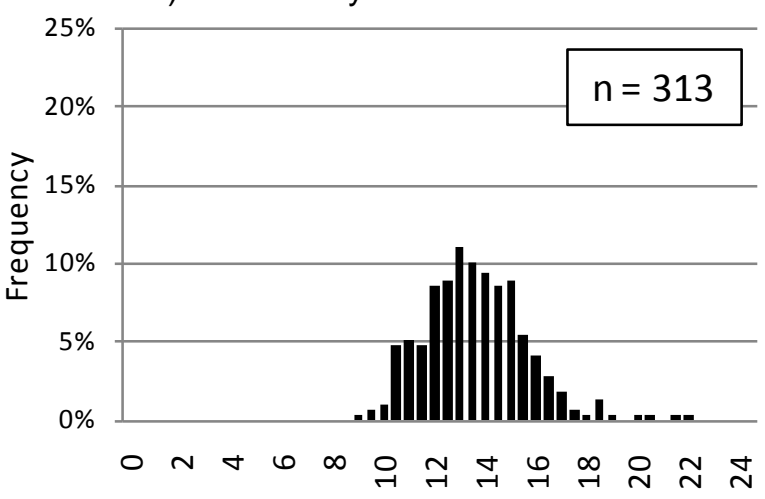

g) Headway between veh. 1 - 8

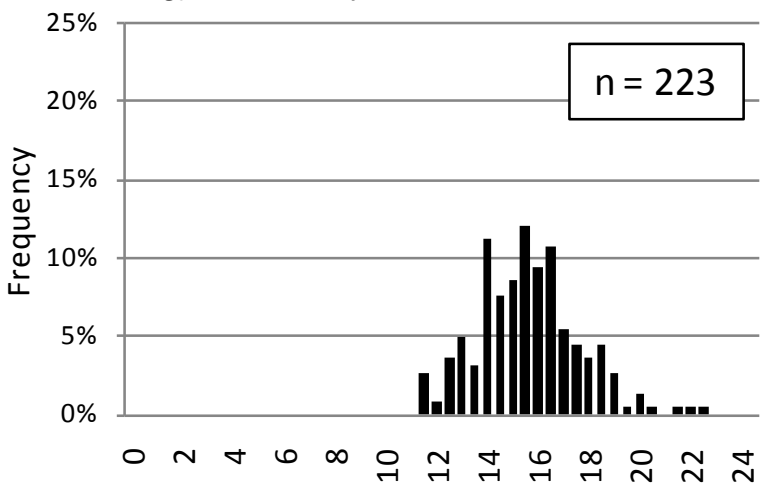

h) Headway between veh. 1 - 9

Figure 6 . Headway distribution between non-consecutive vehicles 


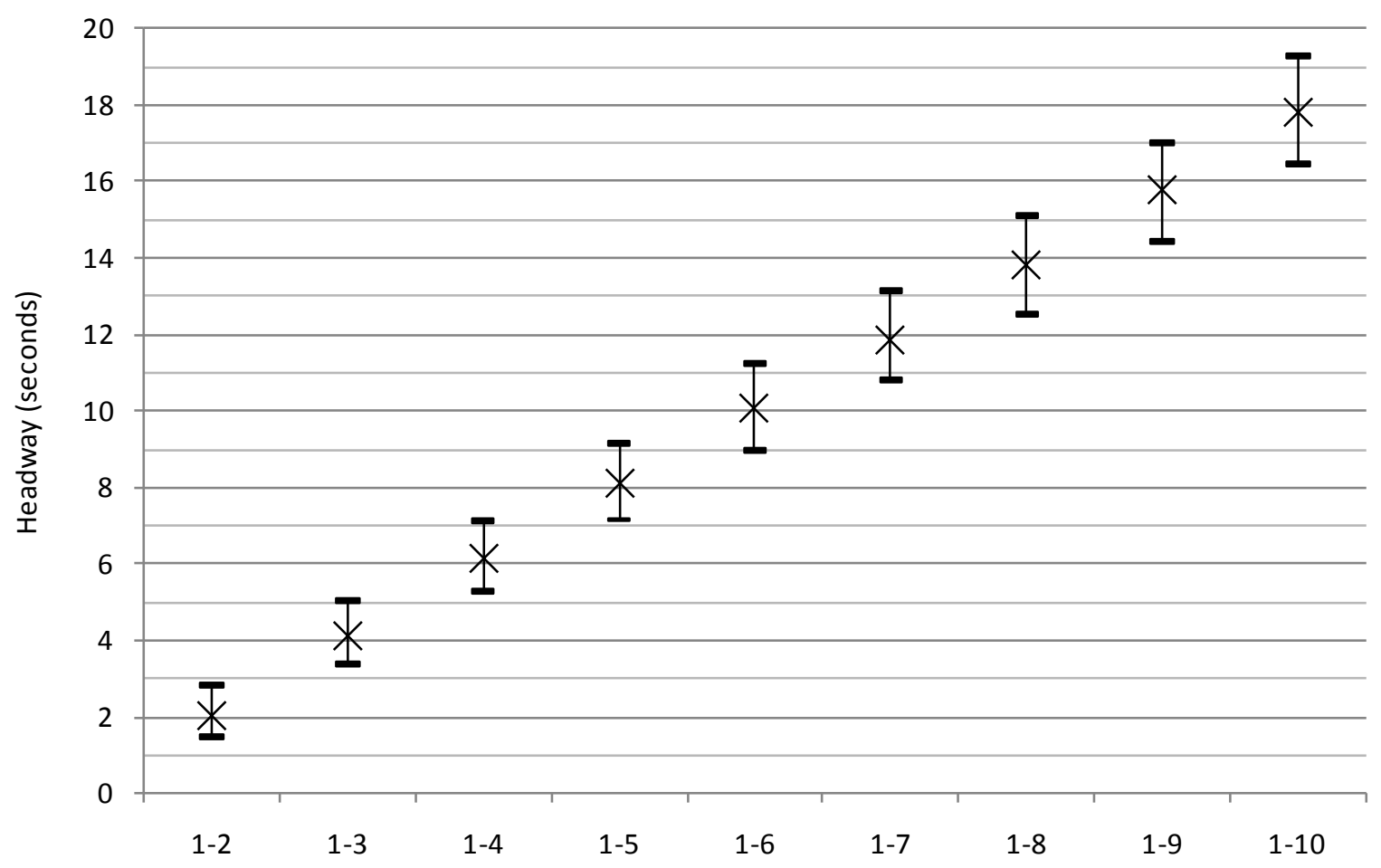

Figure $7.25^{\text {th }}, 50^{\text {th }}$, and $75^{\text {th }}$ Percentile Headways between non-consecutive vehicles during saturated conditions

Table 3. Headway values between non-consecutive vehicles at saturated intersections

\begin{tabular}{|l|c|c|c|c|c|c|c|c|c|}
\hline Headway (seconds) & 1 to 2 & 1 to 3 & 1 to 4 & 1 to 5 & 1 to 6 & 1 to 7 & 1 to 8 & 1 to 9 & 1 to 10 \\
\hline $25^{\text {th }}$ Percentile & 1.47 & 3.37 & 5.28 & 7.16 & 8.99 & 10.82 & 12.51 & 14.43 & 16.46 \\
\hline $50^{\text {th }}$ Percentile & 2.03 & 4.09 & 6.14 & 8.08 & 10.09 & 11.83 & 13.79 & 15.81 & 17.81 \\
\hline $75^{\text {th }}$ Percentile & 2.84 & 5.04 & 7.13 & 9.13 & 11.26 & 13.13 & 15.11 & 17.00 & 19.27 \\
\hline Interquartile Range & 1.37 & 1.67 & 1.84 & 1.97 & 2.27 & 2.32 & 2.60 & 2.56 & 2.81 \\
\hline Count (n) & 690 & 636 & 567 & 498 & 439 & 386 & 316 & 223 & 172 \\
\hline Mean & 2.32 & 4.44 & 6.45 & 8.41 & 10.35 & 12.20 & 13.89 & 16.21 & 18.35 \\
\hline Standard Deviation & 1.97 & 2.97 & 2.29 & 2.32 & 2.47 & 2.72 & 2.02 & 4.48 & 6.27 \\
\hline
\end{tabular}




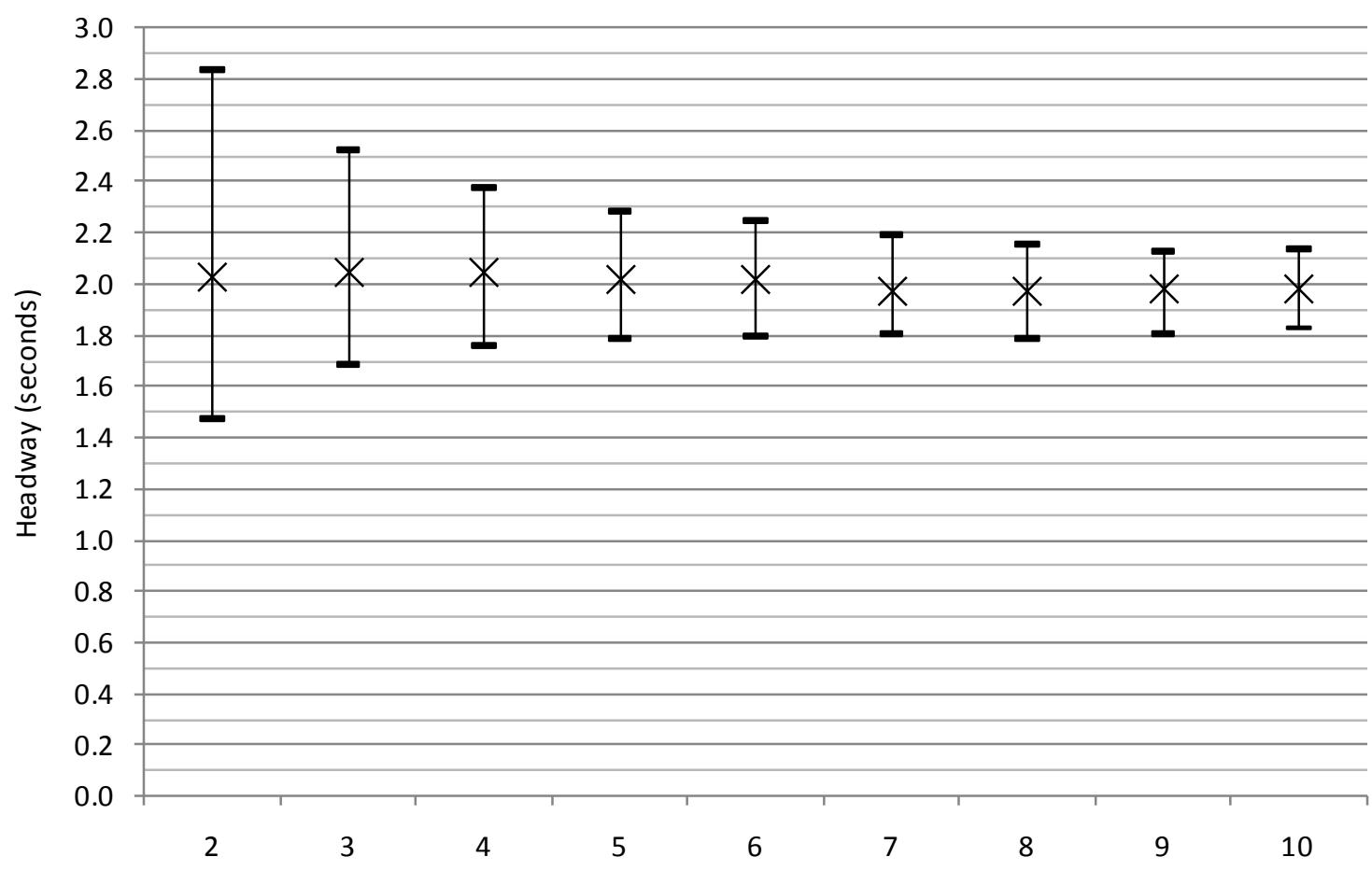

a) Headway distributions with $25^{\text {th }}$, median, and $75^{\text {th }}$ percentiles

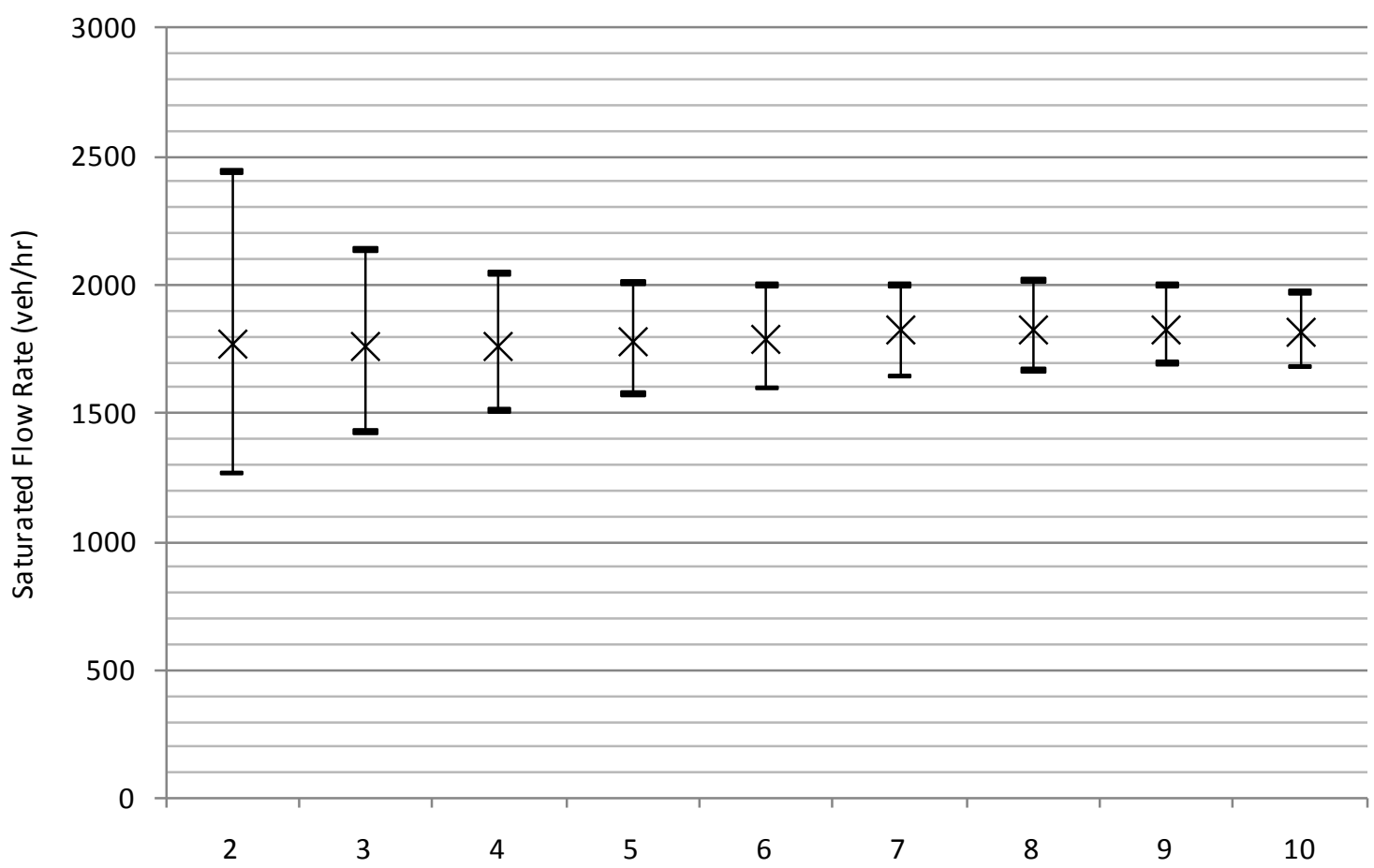

b) Saturated Flow Rates with $25^{\text {th }}$, median, and $75^{\text {th }}$ percentiles

Figure 8. Average Headways between vehicles in saturated conditions based on vehicles in queue 